\title{
Sexual risk behaviour of Canadian participants in the first efficacy trial of a preventive HIV-1 vaccine
}

\author{
Thomas M. Lampinen, Keith Chan, Robert S. Remis, Maraki Fikre Merid, Melanie Rusch, \\ Jean Vincelette, Ken Logue, Vladimir Popovic, Michel Alary, Martin T. Schechter, Robert S. Hogg
}

Abstract

Background: Phase I and phase II HIV-1 vaccine trials have revealed increases in risky sexual activity among study subjects during the trials, perhaps because the subjects believe that the vaccine being tested is efficacious; subjects may thus suffer harm from their participation. We evaluated the sexual behaviour of Canadian men who have sex with men (MSM) who participated in the phase III Vax004 trial of an HIV-1 vaccine.

Methods: Using self-reports of sexual behaviours during the 6 months before trial entry as a baseline, we determined changes in reported sexual behaviour after 6, 12 and 18 months of participation in the trial.

Results: Of 291 HIV-seronegative MSM enrolled from July to October 1999, 260 (89\%) completed 18 months of follow-up, 19 (7\%) experienced seroconversion, and 12 (4\%) did not complete follow-up. Unprotected receptive anal intercourse during the previous 6 months with partners whose HIV-1 serostatus was positive or unknown was reported by $21 \%$ of men at enrolment and by $27 \%$ at any point during 18 months of followup. No increase in this behaviour from baseline was reported by participants, including among men who were motivated to enrol because of expected protection from HIV-1 infection, men who believed they had received the vaccine, men who believed that the vaccine had greater than $50 \%$ efficacy, or men who believed that they had received the vaccine and that vaccine efficacy was greater than $50 \%$.

Interpretation: MSM can be successfully enrolled in HIV-1 vaccine efficacy trials without evident increases in those sexual behaviours most associated with HIV-1 risk.

CMAJ 2005; 172(4):479-83

$\mathrm{D}$ evelopment of preventive $\mathrm{HIV}-1$ vaccines requires clinical trials that effectively recruit, enrol and retain high-risk subjects, including men who have sex with men (MSM). Since candidate vaccines may prove to have little or no efficacy, these trials must also strive to minimize harms associated with participation. A major con$\stackrel{\infty}{-}$ cern has been that trial participants might believe vaccination affords some protection and therefore increase their sexual risk-taking..$^{1,2}$ This concern derives in part from increases in unprotected anal intercourse observed during phase I and phase II vaccine trials. For example, selfreports of unprotected insertive anal intercourse during the previous 6 months increased among 44 gay men enrolled in
San Francisco trials, from 9\% at enrolment to $20 \%$ at the 12-month assessment; however, the HIV status of sexual partners was not assessed. ${ }^{1}$ The world's first phase III trial to evaluate a candidate preventive $\mathrm{HIV}-1$ vaccine was recently completed in North America and Europe. ${ }^{2}$ A consortium sponsored by the Canadian Network for Vaccines and Immunotherapeutics of Cancer and Chronic Viral Diseases (CANVAC) was formed to assess participation, retention and change in sexual risk behaviour at trial sites in this country. We report here the Canadian experience in this trial through 18 months of follow-up and assess trends in high-risk sexual behaviour reported by participants.

\section{Methods}

MSM were recruited by print advertisements and outreach in Montreal, Toronto, Vancouver and other sites in North America and Europe to participate in the Vax004 trial, a randomized, placebo-controlled evaluation of a bivalent recombinant gp120 HIV-1 subtype B vaccine (AIDSVAX B/B, Vaxgen Inc., Brisbane, Calif.). ${ }^{2} \mathrm{HIV}$-seronegative MSM from 18 to 60 years of age who reported anal intercourse during the previous 12 months and who were not involved in a continuous monogamous relationship with an HIV-negative partner during the same period were eligible to participate. Men were ineligible if they felt unable to complete 3 years of follow-up or reported previous injection drug use, HIV-1 vaccination, receipt of another vaccine or immunoglobulin during the 2 weeks before enrolment or receipt of a live-attenuated vaccine during the 4 weeks before enrolment.

Following screening, eligible participants were asked to return for baseline and then semiannual follow-up visits for 36 months. At each visit, vaccination, medical evaluations and structured risk assessment interviews were performed, and risk reduction counselling was provided. The risk assessments elicited self-reports of sexual behaviour according to the HIV-1 status of partners (seronegative, seropositive or status unknown). Behavioural assessments were discontinued if HIV-1 seroconversion, the primary trial end point, occurred.

The baseline questionnaire included questions about whether enrolment in the trial had been motivated by a belief that vaccination would provide protection against HIV-1 (grouped in the present analysis as any level of agreement $\mathrm{v}$. other) and about perceived vaccine efficacy (grouped in the present analysis as efficacy $>50 \%$ v. efficacy $\leq 50 \%$ or don't know). The 12 -month follow-up questionnaire asked participants if they believed they had received vaccine or placebo or didn't know (grouped as vaccine v. other). Ethical review boards at each site approved the 
trial protocol, and participants provided written informed consent; the consent form specified the 2:1 ratio of assignment to vaccine or placebo.

The present study represents secondary analyses using trial data that were requested by CANVAC collaborators and provided by the trial sponsor. Groups were compared using $\chi^{2}$ and Fisher's exact tests for categorical variables and Wilcoxon rank-sum and Kruskall-Wallis statistics for continuous variables. The percentage of men reporting unprotected anal intercourse by 18 months' follow-up (defined as any unprotected encounter during the period between study visits) was estimated using life table methods, and groups were compared using log-rank tests; in these analyses, data for men who experienced seroconversion and those who dropped out or were withdrawn prematurely from the trial were censored following their last risk assessment. We compared participants whose data was censored with those who completed follow-up. Because this comparison would be confounded by trial site (associated with both censorship and high-risk behaviours), we matched each participant whose data were censored with 4 randomly selected participants who had completed 18 months of follow-up at the same site.

The primary behavioural end point was unprotected receptive anal intercourse with a partner whose HIV-1 serostatus was positive or unknown. However, incomplete assessment of the behaviour of high-risk participants (because of seroconversion or dropping out) could lead to selection of a progressively lower-risk group, thereby producing the spurious impression of a decline in overall risk behaviour during follow-up. To guard against this bias, in these analyses we made the following conservative ("worst case") assumption for every follow-up assessment that was missing: we assumed that these participants would have reported engaging in unprotected receptive anal intercourse with partners of positive or unknown serostatus at these times.
Change in sexual risk behaviour was assessed using paired (McNemar's) tests that compared participants' behaviour before enrolment with that reported at the 6-, 12- and 18-month followup visits.

\section{Results}

From July to October 1999, 291 MSM enrolled in the Vax004 trial at 3 Canadian sites (105 in Vancouver, 99 in Montreal and 87 in Toronto). The median age of participants was 37 years, and most had received some college education (Table 1). Significant differences were observed across sites with respect to participants' level of education, reasons for joining the study and recent recreational drug use; as well, site-specific differences were observed with respect to recent diagnosis of STDs and percentage of men reporting sexual relations during the 6 months before enrolment with HIV-positive, HIV-negative and statusunknown partners. Among men who had an HIV-positive or status-unknown partner, the percentage engaging in unprotected receptive anal intercourse with each type of partner was not materially different across sites (site-specific data available from the authors upon request).

During 18 months of follow-up, data for $11 \%$ of the men were censored because of seroconversion $(n=19)$ or because of withdrawal from the trial or loss to follow-up $(n=12)$. The number of men for whom data were censored before their 6-, 12- and 18-month follow-up visits were 6, 19 and 6 , respectively. The percentage of men for whom data were censored at each site differed significantly (Mon-

Table 1: Characteristics of Canadian Vax004 trial participants at enrolment

\begin{tabular}{|c|c|c|c|c|}
\hline \multirow[b]{2}{*}{ Characteristic } & \multicolumn{3}{|c|}{ Group; no. (\%) of participants* } & \multirow[b]{2}{*}{$p$ value } \\
\hline & $\begin{array}{c}\text { All } \\
n=291\end{array}$ & $\begin{array}{c}\text { With } \\
\text { censored data } \\
n=31\end{array}$ & $\begin{array}{l}\text { Matched } \\
\text { controls } \\
n=124\end{array}$ & \\
\hline Median age (IQR), yr & $37(31-43)$ & $35(31-41)$ & $37.5(32-43)$ & 0.16 \\
\hline Postsecondary education & $208(71)$ & $23(74)$ & $92(74)$ & $>0.99$ \\
\hline \multicolumn{5}{|l|}{ Motive for joining study } \\
\hline Some HIV-1 protection & $129(44)$ & $16(52)$ & $62(50)$ & 0.87 \\
\hline $\begin{array}{l}\text { Believed vaccine efficacy } \\
>50 \%\end{array}$ & $68(23)$ & $4(13)$ & $32(26)$ & 0.13 \\
\hline \multicolumn{5}{|l|}{ Drug use $\ddagger$} \\
\hline Marijuana & $140(48)$ & $17(55)$ & $61(40)$ & 0.57 \\
\hline $\begin{array}{l}\text { Volatile nitrite inhalants } \\
\text { ("poppers") }\end{array}$ & $126(43)$ & $16(52)$ & $61(40)$ & 0.81 \\
\hline Crack cocaine & $7 \quad(2)$ & $1 \quad(3)$ & $3 \quad(2)$ & $>0.99$ \\
\hline Amphetamines & $37(13)$ & $10(32)$ & $14(11)$ & 0.01 \\
\hline Tranquilizers & $30(10)$ & $6(19)$ & $17(14)$ & 0.41 \\
\hline Hallucinogens & $65(22)$ & $11(35)$ & $33(27)$ & 0.33 \\
\hline Cocaine (snorted) & $42(14)$ & $6(19)$ & 18 (15) & 0.58 \\
\hline Viagra & $37(13)$ & $6(19)$ & $21(17)$ & 0.75 \\
\hline
\end{tabular}


treal 2/99 [2\%], Vancouver 12/105 [11\%] and Toronto $17 / 87$ [20\%], $p<0.001)$. Compared with the matched controls (who remained HIV-1 seronegative), MSM for whom data were censored were more likely to report recreational use of amphetamines (Table 1), as well as unprotected sex with HIV-positive and status-unknown partners during the 6 months before their enrolment and greater numbers of HIV-positive partners (Table 2).

At enrolment, 61 (21\%) of the 291 men reported having engaged in unprotected receptive anal intercourse during the previous 6 months with partners whose HIV-1 status was positive or unknown. The prevalence of this behaviour at the 6-, 12- and 18-month follow-up visits was 20\%, $20 \%$ and $18 \%$, respectively, using the most conservative assumption (that men with censored or missing data had engaged in risky behaviour); the matched-pair odds ratios indicated no significant change in participants' behaviour from base- line to any of these time points (Table 3). Furthermore, we did not observe any change in this behaviour among subgroups of participants who did and did not report a motivation to enter the trial for protection from HIV-1 infection, a belief that they had received the vaccine, a belief that vaccine efficacy was greater than $50 \%$, or a belief that they had received vaccine and that vaccine efficacy was greater than $50 \%$ (data not shown).

The cumulative percentage of men reporting unprotected receptive anal intercourse with an HIV-positive or statusunknown partner at any point during 18 months of followup was $27 \%$. The cumulative probability of engaging in this behaviour at any point during 18 months of follow-up was not significantly greater among men who reported being motivated to enrol in the trial for protection from HIV-1 infection, those who believed they had received vaccine, those who believed that vaccine efficacy was greater than $50 \%$, or

Table 2: Sexual behaviour of Canadian Vax004 trial participants during the 6 months before enrolment, as reported at enrolment

\begin{tabular}{|c|c|c|c|c|}
\hline \multirow[b]{2}{*}{ Sexual behaviour } & \multicolumn{3}{|c|}{ Group; no. (\%) of participants* } & \multirow[b]{2}{*}{$p$ value } \\
\hline & $\begin{array}{c}\text { All } \\
n=291\end{array}$ & $\begin{array}{c}\text { With } \\
\text { censored data } \\
n=31\end{array}$ & $\begin{array}{l}\text { Matched } \\
\text { controls } \\
n=124\end{array}$ & \\
\hline \multicolumn{5}{|l|}{ No. with male partner } \\
\hline HIV-1 positive & $124(43)$ & $20(65)$ & $60(48)$ & 0.11 \\
\hline HIV-1 negative & $127(44)$ & $14(45)$ & $53(43)$ & 0.81 \\
\hline HIV-1 status unknown & $233(80)$ & $26(84)$ & $93(75)$ & 0.30 \\
\hline \multicolumn{5}{|l|}{$\begin{array}{l}\text { Median no. of male partners } \\
\text { (IQR) }\end{array}$} \\
\hline Total & $7(4-20)$ & $10(4-30)$ & $7.5(3-15)$ & 0.20 \\
\hline HIV-1 positive & $1(1-2) \ddagger$ & $1(0-2)$ & $0(0-1)$ & 0.01 \\
\hline HIV-1 negative & $2(1-4) \ddagger$ & $0(0-3)$ & $0(0-2)$ & 0.69 \\
\hline HIV-1 status unknown & $7(4-20) \ddagger$ & $7(2-20)$ & $7(2-20)$ & 0.35 \\
\hline \multicolumn{5}{|l|}{ HIV-1 positive partner } \\
\hline Unprotected oral & $32(26) \ddagger$ & $9(29)$ & $13(10)$ & 0.02 \\
\hline Unprotected anal receptive & 19 (15)‡ & $6(19)$ & $7 \quad(6)$ & 0.02 \\
\hline Unprotected anal insertive & 43 (35)‡ & $10(32)$ & $21(17)$ & 0.06 \\
\hline \multicolumn{5}{|l|}{ HIV-1 negative partner } \\
\hline Unprotected oral & 62 (49)‡ & $6(19)$ & $25(20)$ & 0.92 \\
\hline Unprotected anal receptive & $43(34) \ddagger$ & $6(19)$ & $18(15)$ & 0.58 \\
\hline Unprotected anal insertive & $52(41) \ddagger$ & $5(16)$ & $22(18)$ & 0.82 \\
\hline \multicolumn{5}{|l|}{$\begin{array}{l}\text { HIV-1 status unknown } \\
\text { partner }\end{array}$} \\
\hline Unprotected oral & 109 (47)‡ & $18(58)$ & $42(34)$ & 0.02 \\
\hline Unprotected anal receptive & 45 (19)‡ & $9(29)$ & $17(14)$ & 0.06 \\
\hline Unprotected anal insertive & 71 (30)‡ & $12(39)$ & $33(27)$ & 0.18 \\
\hline \multicolumn{5}{|l|}{$\begin{array}{l}\text { HIV-1 positive or status } \\
\text { unknown partner }\end{array}$} \\
\hline Unprotected anal receptive & 60 (23)‡ & $12(39)$ & $24(19)$ & 0.02 \\
\hline Unprotected anal insertive & 95 (36)‡ & $17(55)$ & $44(35)$ & 0.05 \\
\hline Any unprotected anal sex & 116 (44)‡ & $19(61)$ & $52(42)$ & 0.05 \\
\hline
\end{tabular}


those who believed that they had received the vaccine and that vaccine efficacy was greater than $50 \%$ (Table 4). The cumulative percentage of men who reported unprotected receptive anal intercourse with any partner at any point during follow-up was $40 \% ; 13 \%$ of men reportedly engaged in this behaviour with HIV-negative partners only, 14\% with HIV-positive or status-unknown partners only, and $13 \%$ with both HIV-negative and HIV-positive or status-unknown partners. With regard to the latter group, we did not assess the temporal ordering of such encounters.

\begin{tabular}{|c|c|c|c|}
\hline $\begin{array}{l}\text { Time of } \\
\text { assessment }\end{array}$ & $\begin{array}{c}\text { No. }(\%) \\
\text { of subjects } \\
n=291\end{array}$ & OR† $(95 \% \mathrm{Cl})$ & $p$ value \\
\hline Enrolment & $61(21)$ & 1.0 & \\
\hline $6 \mathrm{mo}$ & $58(20)$ & $0.9(0.5-1.4)$ & 0.81 \\
\hline $12 \mathrm{mo \S}$ & $57(20)$ & $0.9(0.5-1.4)$ & 0.71 \\
\hline 18 mo & $52(18)$ & $0.8(0.4-1.2)$ & 0.34 \\
\hline
\end{tabular}

Note: $\mathrm{OR}=$ odds ratio, $\mathrm{Cl}=$ confidence interval.

*Using the most conservative assumption that subjects with censored or missing data engaged in this behaviour.

†Matched-pair OR indicating the likelihood of high-risk behaviour at follow-up, compared with enrolment.

łIncludes 6 censored and 2 missing observations.

slncludes 25 censored and 1 missing observation.

I Includes 31 censored and 1 missing observation.

\section{Interpretation}

Among Canadian MSM enrolled in the Vax004 trial, we observed no significant change in high-risk unprotected receptive anal intercourse between enrolment and the 6-, 12and 18-month follow-up assessments. This result has special importance, given the announcement by the trial sponsors that the AIDSVAX vaccine did not provide protection from HIV-1 infection. ${ }^{3}$

The percentage of trial participants reporting any unprotected receptive anal intercourse is consistent with that reported in contemporary studies of MSM in these cities. ${ }^{46}$ However, the Vax004 trial questionnaire also assessed the HIV-1 status of partners with whom such intercourse occurred. Importantly, $21 \%$ of the 291 trial participants (including $15 \%$ [16/105] of those in Vancouver) reported that during the 6 months before enrolment they had engaged in unprotected receptive anal intercourse with a partner whose HIV-1 status was positive or unknown. For comparison, we recently reported that only $14 \%$ of 282 young MSM in a cohort study in Vancouver engaged in this behaviour during the previous 12 months $^{7}$ but that most HIV-1 seroconversions occurred in such men. Thus, despite intensive counselling, Canadian participants in the Vax004 trial appeared to be at relatively high risk for HIV1 infection. If subsequent analyses confirm that seroconversion during the trial occurred mainly among men who reported unprotected receptive anal intercourse with partners

Table 4: Life table estimates of the probability of reporting unprotected receptive anal intercourse with a partner whose HIV-1 serostatus was positive or unknown (URAI) at any point during the 18 months following enrolment in the Vax004 vaccine trial, by participants' motivation and beliefs

\begin{tabular}{|c|c|c|c|}
\hline Motivation or belief & $\begin{array}{l}\text { No. }(\%) \text { of } \\
\text { subjects } \\
n=291\end{array}$ & $\begin{array}{l}\text { Probability of URAI } \\
\text { during } 18 \text {-mo } \\
\text { follow-up }\end{array}$ & $p$ value \\
\hline $\begin{array}{l}\text { Participant enrolled fo } \\
\text { from HIV-1 infection* }\end{array}$ & & & \multirow[t]{3}{*}{0.48} \\
\hline Yes & $129(44)$ & 0.29 & \\
\hline No & $162(56)$ & 0.25 & \\
\hline $\begin{array}{l}\text { Participant believed th } \\
\text { received vaccine } \dagger\end{array}$ & & & \multirow[t]{3}{*}{0.45} \\
\hline Yes & $50(19)$ & 0.30 & \\
\hline No & $215(91)$ & 0.25 & \\
\hline $\begin{array}{l}\text { Participant believed th } \\
\text { efficacy was }>50 \% *\end{array}$ & & & \multirow[t]{3}{*}{0.84} \\
\hline Yes & $68(23)$ & 0.27 & \\
\hline No & $223(77)$ & 0.26 & \\
\hline $\begin{array}{l}\text { Participant believed th } \\
\text { received vaccine } \dagger \text { and } \\
\text { efficacy was }>50 \%\end{array}$ & & & \multirow[t]{3}{*}{0.52} \\
\hline Yes & $19 \quad(7)$ & 0.32 & \\
\hline No & $246(93)$ & 0.25 & \\
\hline
\end{tabular}

*Assessed at time of enrolment.

†Participant's belief that he had received vaccine or placebo or didn't know (grouped as vaccine $v$. other) was assessed at the 12 -month follow-up visit; 26 observations were missing. 
whose HIV-1 serostatus was positive or unknown, the findings will have important implications for targeting preventive interventions to MSM and for selecting high-risk participants for future vaccine efficacy trials.

There are several limitations to the present study. First, assessment of whether trial participation per se was associated with behavioural change is not possible, since the Vax004 trial lacked a comparison group of MSM who received neither vaccine nor placebo. Nevertheless, it is reassuring that, despite conservative assumptions in our analysis, we found no evidence of an increase in the sexual risk behaviour of trial participants; during the same calendar period, substantial increases in risk behaviours among MSM in North America and Europe were reported. ${ }^{8}$ Second, selfreports of sexual behaviours are subject to social desirability effects that may produce underestimates of risk. Third, if participants with censored data are more likely than those completing follow-up to begin unprotected anal intercourse, the cumulative percentages we report may be underestimates by as much as several percentage points. Finally, trial participants may not be representative of other MSM, and caution should be used in generalizing our results. Indeed, if highrisk MSM tend to enrol in vaccine trials, ${ }^{1,9,10}$ regression to the mean could explain reductions in sexual risk behaviours that might be reported from vaccine trials lacking a comparison group that receives neither vaccine nor placebo.

The largest number of incident HIV-1 infections and AIDS diagnoses reported in Canada continues to be among MSM. ${ }^{11}$ Recent clinically motivated shifts toward delayed or interrupted prescribing of antiretroviral therapy ${ }^{12-14}$ are expected to yield a net increase in the infectiousness of HIV-positive sexual partners. This increase may, in turn, portend increases in $\mathrm{HIV}-1$ seroincidence among MSM. ${ }^{15}$ Our results demonstrate that high-risk MSM in Canada can be successfully recruited, enrolled and retained in HIV1 vaccine efficacy trials, and they underscore the importance of continued counselling and sexual risk measurements during such studies. ${ }^{12}$

\section{This article has been peer reviewed.}

From the British Columbia Centre for Excellence in HIV/AIDS, Vancouver, BC (Lampinen, Chan, Rusch, Schechter, Hogg); the Department of Health Care and Epidemiology, University of British Columbia, Vancouver, BC (Lampinen, Rusch, Schechter, Hogg); the Department of Public Health Science, University of Toronto, Toronto, Ont. (Remis, Merid); Hôpital Saint-Luc du Centre hospitalier de l'Université de Montréal (CHUM), Montréal, Que. (Vincelette); University Health Network, Toronto General Hospital, Toronto, Ont. (Logue); Vaxgen Inc., Brisbane, Calif. (Popovic); and the Population Health Research Unit, Centre hospitalier affilié universitaire de Québec and Université Laval, Québec, Que. (Alary). Robert Remis is coordinator of CANVAC Project 1.5 (Behavioural and Epidemiological Aspects of HIV Vaccine Trials), and Robert Remis, Jean Vincelette and Michel Alary are coinvestigators with the project.

Competing interests: Vladimir Popovic was, at the time this study was performed, an employee of Vaxgen Inc. None declared for all other authors.

Contributors: Thomas Lampinen designed the study with assistance from Robert Remis, Martin Schechter and Robert Hogg. Data were collected and managed by Robert Remis, Jean Vincelette, Ken Logue, Vladimir Popovic, Michel Alary, Robert Hogg and Maraki Fikre Merid and analyzed by Thomas Lampinen, Keith
Chan and Melanie Rusch. Thomas Lampinen wrote the report. All authors contributed to the revision of various drafts and approved the final version of the submitted manuscript.

Acknowledgements: We are indebted to the 291 Canadian men enrolled in the Vax004 trial. We thank Vaxgen Inc. for providing the trial data. For clinical and logistic support with the study, we thank Anne-Marie Bourgault, Joseph De Wet, Christiane Gaudreau, Peter Granger, Marianne Harris, Val Montessori, Carol Murphy, Michael V. O'Shaughnessy, Peter Phillips, Mark Tyndall, Robert Voigt, Phil Sestak, Brian Willoughby and Brian Woodfall, as well as Eric Demers, Liz Ferris, Lesley Gallagher, Roger Le Clerc, Nancy McLean, P. Pellerin (deceased) and Jean Roy. Funding for this study was provided by the Canadian Network for Vaccines and Immunotherapeutics of Cancer and Chronic Viral Diseases (CANVAC Project 1.5, Behavioural and Epidemiological Aspects of HIV Vaccine Trials). Thomas Lampinen, Robert Hogg and Melanie Rusch are supported by the Michael Smith Foundation for Health Research.

\section{References}

1. Chesney MA, Chambers DB, Kahn JO. Risk behavior for HIV infection in participants in preventive HIV vaccine trials: a cautionary note. 7 Acquir Immune Defic Syndr Hum Retrovirol 1997;16(4):266-71.

2. Francis DP, Heyward WL, Popovic V, Orozco-Cronin P, Orelind K, Gee C, et al. Candidate HIV/AIDS vaccines: lessons learned from the world's first phase III efficacy trials. AIDS 2003;17(2):147-56.

3. Pollack A, Altman LK. Large trial finds AIDS vaccine fails to stop infection. New York Times 2003 Feb 24;Sect A:1(col 1).

4. Dufour A, Alary M, Otis J, Remis RS, Masse B, Turmel B, et al. Risk behaviours and HIV infection among men having sexual relations with men: baseline characteristics of participants in the Omega Cohort Study, Montreal, Quebec, Canada. Can 7 Public Health 2000;91(5):345-9.

5. Piaseczna MA, Craib KJ, Li K, Chan K, Weber AE, Strathdee SA, et al. Longitudinal patterns of sexual behavior and condom use in a cohort of HIV-negative gay and bisexual men in Vancouver, British Columbia, Canada, 1995 2000. 7 Acquir Immune Defic Syndr 2001;28(2):187-93.

6. Calzavara L, Burchell AN, Major C, Remis RS, Corey P, Myers T, et al. Increases in HIV incidence among men who have sex with men undergoing repeat diagnostic HIV testing in Ontario, Canada. AIDS 2002;16(12):1655-61.

7. Lampinen TM, Chan K, Craib KJP, Miller ML, Schilder AJ, Devlin B, et al. Relation between partner HIV-1 status, condom use, and HIV-1 seroincidence among men who have sex with men (MSM) in Vancouver, 2001-2002 [poster presentation]. 12th annual Canadian Conference on HIV/AIDS Research; 2003 Apr 11; Halifax.

8. Wolitski RJ, Valdiserri RO, Denning PH, Levine WC. Are we headed for a resurgence of the HIV epidemic among men who have sex with men? Am 7 Public Health 2001;91(6):883-8.

9. Buchbinder SP, Douglas JM Jr, McKirnan DJ, Judson FN, Katz MH, MacQueen KM. Feasibility of human immunodeficiency virus vaccine trials in homosexual men in the United States: risk behavior, seroincidence, and willingness to participate. 7 Infect Dis 1996;174(5):954-61.

10. O'Connell JM, Hogg RS, Chan K, Strathdee SA, McLean N, Martindale SL, et al. Willingness to participate and enroll in a phase 3 preventive HIV-1 vaccine trial. 7 Acquir Immune Defic Syndr 2002;31(5):521-8.

11. Geduld J, Gatali M, Remis RS, Archibald CP. Estimates of HIV prevalence and incidence in Canada, 2002. Can Commun Dis Rep 2003;29(23):197-207.

12. Dybul M, Fauci AS, Bartlett JG, Kaplan JE, Pau AK. Guidelines for using antiretroviral agents among HIV-infected adults and adolescents. Ann Intern Med 2002;137(5 Pt 2):381-433.

13. Pomerantz RJ. Initiating antiretroviral therapy during HIV infection: confusion and clarity. $7 A M A$ 2001;286(20):2597-9.

14. Yeni PG, Hammer SM, Carpenter CC, Cooper DA, Fischl MA, Gatell JM, et al. Antiretroviral treatment for adult HIV infection in 2002: updated recommendations of the International AIDS Society-USA Panel. FAMA 2002;288 (2):222-35.

15. Lampinen TM, Baggaley R, Garnett GP, Gataric N, Schechter MT, Montaner JS, et al. Reversion to pre-HAART population levels of viremia concomitant with recent changes in ART prescribing practices [poster abstract TuPeC4722, 15th International AIDS Conference]. Medscape Gen Med [serial online] 2004;6(3). Available: www.iasociety.org/ejias/show.asp?abstract_id= 2175412 (accessed 2005 Jan 12).

Correspondence to: Dr. Thomas M. Lampinen, BC Centre for Excellence in HIVIAIDS, 608-1081 Burrard St., Vancouver BC V6Z1Y6; fax 604 806-9044; tlampinen@cfenet.ubc.ca 